\title{
An observational study to evaluate fall in hemoglobin following abortions conducted by misoprostol and surgical methods
}

\author{
Subrata Das, Swapnil Wilson, Somila Xess*
}

Department of Obstetrics and Gynecology, GMC Ambikapur, Chhattisgarh, India

Received: 25 February 2020

Accepted: 27 March 2020

*Correspondence:

Dr. Somila Xess,

E-mail: somilaxess05@gmail.com

Copyright: (C) the author(s), publisher and licensee Medip Academy. This is an open-access article distributed under the terms of the Creative Commons Attribution Non-Commercial License, which permits unrestricted non-commercial use, distribution, and reproduction in any medium, provided the original work is properly cited.

\begin{abstract}
Background: Over the past three decades, medical methods of abortion have been developed throughout the world and are now the standard methods of providing abortion care in addition to surgical methods. There are various differences between the two methods. In this study, evaluating the fall in haemoglobin levels in abortions conducted by misoprostol and $\mathrm{D}$ and $\mathrm{E}$ in women with pregnancy failure.

Methods: Total of 80 women who fulfilled the criteria were included in the study. Inclusion and exclusion criteria applied and $\mathrm{Hb}$ levels noted on day 1 and 15 during follow up. In addition to this induction abortion interval and side effects of both the methods were also studied. Participants assigned to medical treatment received $800 \mu \mathrm{g}$ of misoprostol inserted into posterior vaginal fornix i.e., day $1^{\text {st }}$ and repeat dose on day 3 if no expulsion. Follow up done after 1 week and 15 days, if there was no expulsion, suction and evacuation was done. Participants assigned to dilatation and evacuation group would undergo the procedure in operation theatre. Statistical analysis done.

Results: The mean induction to abortion interval in the misoprostol group was $9.1 \pm 2.1$ hours (mean $\pm \mathrm{SD}$ ). The mean hemoglobin level in the misoprostol group on day 15 was $9.7 \pm 1.12$ and that in the $\mathrm{D}$ and E group was $10.26 \pm 1.31 \mathrm{p}$ value (0.04), statistically significant.

Conclusions: Proper counseling of the side effects in both the methods and prompt action to alarming signs are required to avoid major disaster.
\end{abstract}

Keywords: Abortion, D and E, Misoprostol

\section{INTRODUCTION}

In India, the second most populous country in the world, abortion has been legal on a broad range of grounds since 1971. Over the past three decades, medical methods of abortion have been developed throughout the world and are now the standard methods of providing abortion care. Medical abortion, which involves the use of medications rather than a surgical procedure to induce an abortion, is an option for women who wish to terminate a first trimester pregnancy. The method is most commonly used up to 63 days of gestation but is also effective after. The centres for disease control and prevention estimates that $64 \%$ of abortions are performed before 63 days of gestation. ${ }^{1}$ Medical methods are safe, effective and avoids invasive procedures as in surgical abortion but requires active patient participation and follow up. Surgical methods on the other hand are completed in a single setting, have higher success rate but carries risk of perforation, adhesion formation and may affect the reproductive potential of women. In this study we are evaluating the fall in haemoglobin level in both the methods in women with early pregnancy failure.

Objective of this study was to evaluate the fall in haemoglobin following abortions conducted by misoprostol and D and E.

\section{METHODS}

This is an observational study carried out at Government Medical College Ambikapur from October 2019 to 
February 2020. Total 80 women diagnosed with early pregnancy failure in ultrasound findings were included in the study.

\section{USG findings included}

- A crown-rump length $\geq 6 \mathrm{~mm}$ and no cardiac activity or

- A crown-rump length $<6 \mathrm{~mm}$ and no fetal growth at least 1-week later or

- A gestational sac with absent embryonic pole for at least 1 week.

A written and informed consent was taken and inclusion and exclusion criteria were applied.

\section{Inclusion criteria}

- Gestational age of 12 weeks or less.

- Haemoglobin >9 g/dl

- Not allergic to prostaglandins.

\section{Exclusion criteria}

- Gestational age $>12$ weeks,

- Haemoglobin $<9 \mathrm{~g} / \mathrm{dl}$,

- Scarred uterus

- Currently on anti-coagulants

- Allergic to prostaglandins.

- Excessive vaginal bleeding.

Women were randomly assigned in the medical method or surgical methods of abortion flipping a coin with 40 participants in each group. Age, period of gestation, parity noted along with $\mathrm{Hb}$ concentration.

Participant's assigned to medical treatment received 800 $\mu \mathrm{g}$ of misoprostol inserted into the posterior vaginal fornix on the day of enrolment, i.e., day $1^{\text {st }}$. If expulsion was not complete by day $3^{\text {rd }}$, they received a second dose of misoprostol $(800 \mu \mathrm{g})$ and follow up done after one week during which if there was no expulsion, suction and evacuation was done. Participants assigned to dilatation and evacuation group would undergo the procedure in operation theatre.

Both the groups were asked to come back on day 15 during which USG was done to look for retained products of conception in those who underwent medical methods of abortion and haemoglobin concentration checked. The criterion for successful medical treatment was the diagnosis of complete abortion, established by an endometrial thickness $\leq 15 \mathrm{~mm}$. Medical treatment was considered to have failed if, after the first or second dose of treatment, it was not possible to achieve complete uterine evacuation and a new curettage was needed to complete the process. Associated factors like pain, bleeding, nausea, dizziness, fever was compared in both the groups.

\section{Statistical analysis}

Data were analyzed and statistical analysis done. Chi square test was used for analyzing the differences between the two proportions ( $p<0.05$ was considered significant).

\section{RESULTS}

A total of 150 women who underwent ultrasound were diagnosed to have early pregnancy failure out of which 120 fulfilled the criteria but only 80 agreed to participate in the study and hence included.

Most of the women in both the groups belonged to 23 to 27 years of age, lower socioeconomic status, and gravida 2 with gestational age of 8 to 10 weeks upon admission. There was no significant difference among the two groups regarding age, parity or period of gestation. The (mean \pm SD) age of participants in the medical method was $25 \pm 4.9$ years and that in the surgical method was $25 \pm 3.2$ years $(\mathrm{p}$ value $=1.0000)$.

About $37.5 \%$ were gravida 2 in both the groups whereas primigravida were $30 \%$ in the misoprostol group and $25 \%$ in the surgical group. Multigravida comprised $12.5 \%$ in each group.

Analyzing gestational age of the cases it was found that $12(30 \%)$ and $15(37.5 \%)$ were in 6-8 weeks gestation in misoprostol and D and E group, respectively; 20 (50\%) were in 8-10 weeks gestation in the both groups respectively and the rest $8(20 \%)$ in misoprostol and 5 $(12.5 \%)$ in surgical group with 10-12 weeks of gestation. The clinical parameters are described in Table 1.

Table 1: Clinical characteristics of participants.

\begin{tabular}{|c|c|c|c|c|}
\hline Parameters & \multicolumn{2}{|c|}{ Medical methoc } & \multicolumn{2}{|c|}{ Surgical method } \\
\hline Age (in years) & $\mathbf{N}$ & $\%$ & $\mathbf{N}$ & $\%$ \\
\hline $18-22$ & 10 & $25 \%$ & 7 & $17.5 \%$ \\
\hline $23-27$ & 16 & $40 \%$ & 18 & $45 \%$ \\
\hline $28-32$ & 8 & $20 \%$ & 12 & $30 \%$ \\
\hline$>32$ & 6 & $15 \%$ & 3 & $7.5 \%$ \\
\hline \multicolumn{5}{|c|}{ Obstetric history } \\
\hline $\mathrm{G}_{1}$ & 12 & $30 \%$ & 10 & $25 \%$ \\
\hline $\mathrm{G}_{2}$ & 15 & $37.5 \%$ & 15 & $37.5 \%$ \\
\hline $\mathrm{G}_{3}$ & 8 & $20 \%$ & 10 & $25 \%$ \\
\hline $\mathrm{G}_{4}$ or more & 5 & $12.5 \%$ & 5 & $12.5 \%$ \\
\hline \multicolumn{5}{|c|}{ Gestational age (in weeks) } \\
\hline $6-8$ & 12 & $30 \%$ & 15 & $37.5 \%$ \\
\hline $8-10$ & 20 & $50 \%$ & 20 & $50 \%$ \\
\hline $10-12$ & 8 & $20 \%$ & 5 & $12.5 \%$ \\
\hline
\end{tabular}

The mean induction to abortion interval in the misoprostol group was 9.1 \pm 2.1 hours (mean \pm SD). Eighteen patients $(45 \%)$ had aborted within 6 to 8 hours times span whereas 14 (35\%) had expulsion within 9 to 10 hours while the remaining $8(20 \%)$ had expulsion at 
more than 11 hours. For those who had induction abortion interval more than 11 hours had gestational age $>10$ weeks (Figure 1).

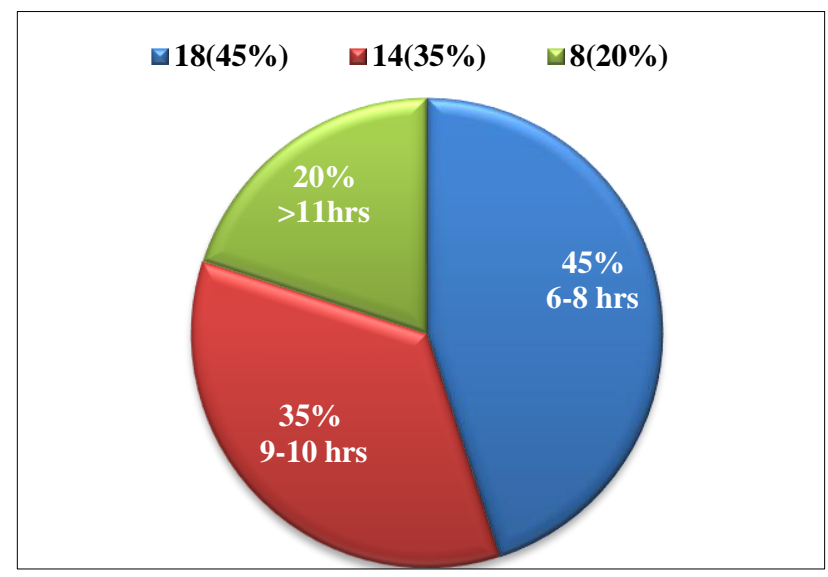

Figure 1: Induction abortion interval.

It was also noted that there was statistically significant difference between the general complaints of the women in both the groups. There was nausea in $20(50 \%)$ participants in the misoprostol group whereas only 6 (15\%) had complaints of nausea in the D and E group.
Dizziness was present in $10(25 \%)$ and $8(20 \%)$ in the misoprostol and D and E group respectively. Eighteen women $(45 \%)$ in the misoprostol group had vomiting in contrast only $2(5 \%)$ had vomiting in the D and E group. A total of $10(25 \%)$ had complaints of diarrhoea and 8 (20\%) had fever in the misoprostol group, on the contrary none such complaints were noted in the surgical methods. Pain and bleeding were also more common among the misoprostol group (Table 2).

Estimation of haemoglobin was done on day 1 as well as day 15 in both the groups. One participant in the misoprostol group had severe bleeding and required immediate transfusion hence excluded from the study. Another two women were lost to follow up while one required evacuation. Therefore, the total number of participants in the misoprostol group was 36 on day 15 of the study. The mean haemoglobin level in the misoprostol group on day 15 was $9.7 \pm 1.12$ and that in the $\mathrm{D}$ and $\mathrm{E}$ group was $10.26 \pm 1.31 \mathrm{p}$ value (0.04), statistically significant. There was much fall in haemoglobin levels in the misoprostol group owing to minor episodes of bleeding throughout the follow up time duration and delay in seeking medical care. Women in the $\mathrm{D}$ and $\mathrm{E}$ group only six had bleeding till 15 days; rest of them had no such complaints (Table 3).

Table 2: General complaints of participants.

\begin{tabular}{|llll|}
\hline Complaints & Misoprostol $\mathbf{n}(\%)$ & $\mathbf{D}$ and $\mathbf{E} \mathbf{n}(\%)$ & Statistical results \\
\hline Nausea & $20(50 \%)$ & $6(15 \%)$ & Chi square $=11.028, \mathrm{DF}=1, \mathrm{p}$ value 0.0009 (significant) \\
\hline Dizziness & $10(25 \%)$ & $8(20 \%)$ & Chi square $=0.283, \mathrm{DF}=1, \mathrm{p}$ value 0.59 (not significant) \\
\hline Vomiting & $18(45 \%)$ & $2(5 \%)$ & Chi square $=16.853, \mathrm{DF}=1, \mathrm{p}$ value 0.0001 (significant) \\
\hline Diarrhoea & $10(25 \%)$ & $0(0 \%)$ & Chi square $=4.158, \mathrm{DF}=1, \mathrm{p}$ value 0.041 (significant) \\
\hline Fever & $8(20 \%)$ & $0(0 \%)$ & Chi square $=8.778, \mathrm{DF}=1, \mathrm{p}$ value 0.003 (significant) \\
\hline Pain & $30(75 \%)$ & $2(5 \%)$ & Chi square $=40.323, \mathrm{DF}=1, \mathrm{p}$ value $<0.0001$ (significant) \\
\hline Bleeding & $28(70 \%)$ & $6(15 \%)$ & Chi square $=24.4, \mathrm{DF}=1, \mathrm{p}$ value $<0.0001$ (significant) \\
\hline
\end{tabular}

Table 3: Haemoglobin levels (day 1 and day 15).

\begin{tabular}{|c|c|c|c|c|c|}
\hline \multirow[b]{2}{*}{$\begin{array}{l}\text { Hb levels } \\
\text { (g/dl) }\end{array}$} & \multicolumn{2}{|c|}{ Misoprostol group } & \multicolumn{2}{|l|}{ D and E group } & \multirow[b]{2}{*}{ Statistical results } \\
\hline & $\begin{array}{l}\text { Day } 1(n=40) \\
n(\%)\end{array}$ & $\begin{array}{l}\text { Day } 15(n=36) \\
n(\%)\end{array}$ & $\begin{array}{l}\text { Day } 1(n=40) \\
n(\%)\end{array}$ & $\begin{array}{l}\text { Day } 15(n=40) \\
n(\%)\end{array}$ & \\
\hline $8-9.9$ & $4(10 \%)$ & $10(27.7 \%)$ & $4(10 \%)$ & $4(10 \%)$ & $\begin{array}{l}\text { Chi square }=3.904, D F=1, p=0.04 \\
\text { (significant) }\end{array}$ \\
\hline $10-10.9$ & $20(50 \%)$ & $22(61.1 \%)$ & $22(55 \%)$ & $26(65 \%)$ & Chi square $=0.12, \mathrm{DF}=1, \mathrm{p}=0.72$ \\
\hline $11-11.9$ & $12(30 \%)$ & $4(11.1 \%)$ & $10(25 \%)$ & $8(20 \%)$ & Chi square $=1.114, \mathrm{DF}=1, \mathrm{p}=0.29$ \\
\hline $12-12.9$ & $4(10 \%)$ & $0(0 \%)$ & $4(10 \%)$ & $2(5 \%)$ & Chi square $=2.02, \mathrm{DF}=1, \mathrm{p}=0.15$ \\
\hline
\end{tabular}

\section{DISCUSSION}

Several studies suggest that management of early pregnancy failure with misoprostol provides an effective alternative to D and E. Published reports emphasize success rates of medical management but provide little information about associated side effects including bleeding and fall in $\mathrm{Hb}$ levels. Expected bleeding patterns are an important part of patient counseling and may influence acceptability and choice of medical versus surgical management.

The most common pattern in the misoprostol group was some bleeding or spotting every day for 15 days. The 
median number of bleeding or spotting days after treatment was 12 . In this analysis, heavy bleeding included the following categories: moderate, heavy or more than two pads/hours. Heavy bleeding was less frequent than light bleeding or spotting. Participants reported a median of 3 days of heavy bleeding. This is one of the major drawbacks in the medical methods leading to the decline in $\mathrm{Hb}$ levels.

In this study, the fall in mean hemoglobin level in the misoprostol group on day 15 was $9.7 \pm 1.12$ and that in the $\mathrm{D}$ and $\mathrm{E}$ group was $10.26 \pm 1.31 \mathrm{p}$ value (0.04), statistically significant. In the study conducted by Prema $\mathrm{K}$, Ramalakshmi $\mathrm{BA}$, while comparing $\mathrm{Hb}$ status in mifepristone versus vaccum aspiration in 303 women. ${ }^{2}$ $\mathrm{Hb}$ estimations done after (40 days) abortion showed that there was no alteration in the mean $\mathrm{Hb}$ levels either in first or second trimester patients. This is contrary to this finding.

In other study conducted by Thonneau P et al, the women who had used the drug combination experienced a mean fall of $0.7 \mathrm{~g} / \mathrm{dl}$ in haemoglobin $(36 \%$ lost $>1 \mathrm{~g} / \mathrm{dl}$ and $8 \%$ $>2 \mathrm{~g} / \mathrm{dl}$ ); haemoglobin concentrations remained stable in women who had vacuum aspiration. ${ }^{3}$ This is similar to this study.

Another study done by Davis et al with $800 \mu \mathrm{g}$ vaginal misoprostol (repeat dose on day $3^{\text {rd }}$ of $800 \mu \mathrm{g}$ if no evacuation) in missed abortion $\leq 13$ weeks gestation showed decreases in haemoglobin levels were greater after misoprostol $(-0.7 \mathrm{~g} / \mathrm{dl})$ than curettage $(-0.2 \mathrm{~g} / \mathrm{dl})(\mathrm{p}$ $<0.001)^{4}$

In the present study $36(90 \%)$ cases in misoprostol group underwent successful evacuation without resorting to surgical intervention. The mean induction to abortion interval was $9.1 \pm 2.1$ hours (mean \pm SD). In a study conducted by Thomas B et al in JIPMER in patients with missed abortion less than 14 weeks with $400 \mu \mathrm{g}$ misoprostol used vaginally showed a mean insertion expulsion time $9.7 \pm 5.6$ hours. ${ }^{5}$ Out of 60 patients $(76.7 \%)$ expelled the products completely. ${ }^{3}$ The present study also showed a similar result. In a similar study done by Singh $\mathrm{K}$ et al. ${ }^{6}$ In women with less than 8 weeks gestation with $800 \mu \mathrm{g}$ vaginal misoprostol followed by a repeat dose of $400 \mu \mathrm{g}$ every 3 hours for a maximum of 3 doses, found a complete evacuation rate of $84.7 \%$ with a mean time interval of 8.1 hours from initial.

The side effects associated with misoprostol are similar to that in other studies. ${ }^{7,8}$ Only one case in this study required transfusion due to heavy bleeding. Rests of the side effects were minor.

\section{CONCLUSION}

Misoprostol is an effective drug for induction of abortion where lesser of expertise is required in comparison to surgical methods. The main complaints is hemorrhage associated, which when not taken care may lead to adverse effects on the health of the women. Hence appropriate patient counselling as well as prompt action is the backbone which may decrease the associated morbidity.

\section{Funding: No funding sources \\ Conflict of interest: None declared \\ Ethical approval: Not required}

\section{REFERENCES}

1. Pazol K, Creanga AA, Zane SB, Burley KD, Jamieson DJ. Abortion surveillance-United States 2009. Centers for Disease Control and Prevention (CDC). MMWR Surveill Summ. 2012;61(SS-8):1-44(Level II-3).

2. Prema K, Ramalakshmi BA. Effect of medical termination of pregnancy on haemoglobin status. Indian J Med Res. 1979;69:605-8.

3. Thonneau P, Poirel H, Fougeyrollas B, Maria B, Meyer L, Goepp A, et al. A comparative analysis of fall in haemoglobin following abortions conducted by mifepristone $(600 \mathrm{mg})$ and vacuum aspiration. Hum. 1995;10(6):1512-5.

4. Davis AR, Hendlish SK, Westhoff C. Bleeding patterns after misoprostol versus surgical treatment of early pregnancy failure, results from an RCT. Am J Obstet Gynecol. 2007;196:31.e1-31.e7.

5. Thomas B, Habeebullah S. Vaginalmisorostol for medical evacuation of early pregnancy failure. JGOG India, 2004;54(4):340-2.

6. Singh K, Fong YF, Dong F. A viable alternative to surgical vacuum aspiration: repeated doses of Intravaginal misoprostol over 9 hours for medical treatment of pregnancies up to 8 weeks. BJOG. 2003; 10:175-80.

7. Shuaib AA. Alharazi AH. Medical versus surgical termination of the first trimester missed miscarriage. Alex J Med. 2013;49(1):13-6.

8. Shokry M, Fathalla M, Hussien M, Eissa AA. Vaginal misoprostol versus vaginal surgical evacuation of first trimester incomplete abortion: comparative study. Middle East Fertil Soc. 2014;19:96-101.

Cite this article as: Das S, Wilson S, Xess S. An observational study to evaluate fall in hemoglobin following abortions conducted by misoprostol and surgical methods. Int J Reprod Contracept Obstet Gynecol 2020;9:2020-3. 